\title{
Alpha6betal integrin expressed by sperm is determinant in mouse fertilization
}

Virginie Barraud-Lange ${ }^{1}$, Nathalie Naud-Barriant ${ }^{1}$, Line Saffar ${ }^{2}$, Liliane Gattegno ${ }^{2}$, Beatrice Ducot ${ }^{3}$, Anne-Sophie Drillet ${ }^{4}$, Morgane Bomsel ${ }^{4}$, Jean-Philippe Wolf*1 and Ahmed Ziyyat ${ }^{1}$

\begin{abstract}
Address: ${ }^{1}$ Biologie de la Reproduction, UFR SMBH, Université Paris 13, Bobigny, France. Service d'Histologie-Embryologie-Cytogénétique, Hôpital Jean Verdier (AP-HP), Bondy, France, ${ }^{2}$ EA 3410 UFR SMBH, Université Paris 13, Bobigny, France, ${ }^{3}$ INSERM-INED Epidémiologie-DémographieSciences sociales, CHU Bicêtre, Le Kremlin-Bicêtre, France and ${ }^{4}$ Entrée Muqueuse du VIH et Immunité Muqueuse, Département de Biologie Cellulaire, Institut Cochin, Université Paris Descartes, CNRS (UMR 8104), Inserm U56, Paris, France

Email: Virginie Barraud-Lange - barraud@smbh.univ-paris13.fr; Nathalie Naud-Barriant - nathalie.naud@wanadoo.fr; Line Saffar - lsaffar@smbh.univ-paris13.fr; Liliane Gattegno - liliane.gattegno@jvr.ap-hop-paris.fr; Beatrice Ducot - ducot@vjf.inserm.fr; AnneSophie Drillet - drillet@cochin.inserm.fr; Morgane Bomsel - bomsel@cochin.inserm.fr; Jean-Philippe Wolf* - jean-philippe.wolf@cch.aphp.fr ; Ahmed Ziyyat - aziyyat@smbh.univ-paris13.fr

* Corresponding author
\end{abstract}

Published: 12 September 2007

BMC Developmental Biology 2007, 7:102 doi:10.1 186/147|-213X-7-102
Received: 18 December 2006

Accepted: 12 September 2007

This article is available from: http://www.biomedcentral.com//47/-2/3X/7// 02

(c) 2007 Barraud-Lange et al; licensee BioMed Central Ltd.

This is an Open Access article distributed under the terms of the Creative Commons Attribution License (http://creativecommons.org/licenses/by/2.0), which permits unrestricted use, distribution, and reproduction in any medium, provided the original work is properly cited.

\begin{abstract}
Background: Based on inhibition tests, the alpha6betal integrin was suggested to be a sperm receptor, but further experiments using gene deletion techniques have shown that neither oocyte alpha6, nor betal integrin subunits were essential for mouse fertilization.

Results: Using Western blot analysis and immunofluorescence, we showed that the mouse sperm expresses the alpha6betal integrin. As for oocyte, binding of $\mathrm{GoH} 3$ anti-alpha6 antibody to sperm induces a specific inhibition of sperm fertilizing ability. Comparing zona-intact and zona-free eggs in fusion tests, we showed that the removal of the zona pellucida by acid treatment bypasses fertilizing oocyte alpha6betal integrin's function in the adhesion/fusion process.

Conclusion: These findings show that alpha6betal integrin is expressed by both gametes and is functional in their membranes interaction. These results and previous reports, about fertilization of alpha6 or betal integrin subunits deleted oocytes by wild type sperm, suggest that the presence of alpha6betal integrin on one of the two gamete membranes can rescue the fertilization process. This hypothesis is further supported by the exchange of membrane fragments occurring between gametes prior to fusion that we recently reported.
\end{abstract}

\section{Background}

Sperm-egg interaction is a complex molecular process leading to gamete fusion mediated by a series of molecular interactions. Evidences have been put forward suggesting the involvement of members of the ADAMs, tetraspanins and integrins families in this mechanism.
Recently, Izumo, a sperm protein belonging to the immunoglobulin superfamily, was found to be essential for the fusion [1]. Three groups reported that Cd9-deficient female mice present a dramatic reduction of their fertility due to a lack of fusion ability of their oocytes [2-4]. We recently showed that double knock-out $C d 9 \% / C d 81 \%$ 
female mice are completely infertile [5] and that, upon fertilization, CD9 tetraspanin controls $\alpha 6 \beta 1$ integrin relocation in patches on the egg membrane [6].

Integrins have also been implicated in sperm-oocyte interaction. Based on several experiments, mouse egg $\alpha 6 \beta 1$ integrin was described to function as a receptor of the sperm fertilin $\beta$. During further experiments, the functionblocking $\mathrm{mAb}$ directed against the $\alpha 6$ integrin subunit, GoH3, turned out to inhibit sperm-oocyte binding, and peptides derived from the sperm fertilin $\beta$ disintegrin domain sequence bind to $\alpha 6 \beta 1$ integrin [7-9]. However, mouse gamete binding and fusion tests using $\mathrm{GoH} 3 \mathrm{mAb}$ gave disparate results, partly according to the technique used for ZP removal $[7,10,11]$. The binding of sperm to mouse oocytes was not inhibited when ZP had been removed using an acidic treatment [12] and the fertilization rate (FR) of cumulus-intact mouse oocytes was not reduced [11]. Recently, we have shown that GoH3 strongly inhibited human sperm-egg fusion when the ZP had been removed by microdissection [6]. Moreover, oocytes from $\alpha 6$ integrin-deficient mice show normal binding and fusion with sperm, suggesting that the $\alpha 6$ integrin is not essential for gamete binding and fusion [11]. These results suggested that the $\alpha 6$ integrin function could be redundant, possibly with another member of the integrin family also expressed on oocyte membrane. However, according to experiments performed by He et al., none of the integrins known to be present on the oocyte are essential for gamete fusion [13].

Major questions about integrins' roles in sperm-oocyte fusion remain unsolved. The possible effect of anti- $\alpha 6 \beta 1$ antibodies on mouse sperm functions has never been addressed, whereas expression of $\alpha 6 \beta 1$ integrin on human spermatozoa has already been reported. The integrin subunits $\alpha 4, \alpha 5$ and $\alpha 6$ have also been detected on normal human sperm using flow cytometry, their expressions being reduced in cases of terato- or oligoasthenoteratozoospermia [14]. The $\beta 1$ integrin subunit has been detected by histochemistry on basement membrane of the tubuli seminiferi, spermatocytes, spermatids and spermatozoa in human [15]. Furthermore, a positive correlation between the expression of $\beta 1$ integrin on human spermatozoa and their fertilizing ability has been demonstrated suggesting that sperm integrins may be determinant in egg-sperm recognition and interaction $[16,17]$. Hence, Reddy et al. proposed $\alpha 6 \beta 1$ integrin as a clinical marker to evaluate sperm quality [16]. Several other studies performed on human sperm demonstrated correlations between their level of integrin expression and their fertilization ability [18-20]. The presence of sperm integrin in human raises the question of its possible expression by mouse sperm. In spite of numerous experiments involving the anti- $\alpha 6 \mathrm{mAb} \mathrm{GoH} 3$ in mouse gamete interaction, this point has never been investigated and discussed, whereas it can account for some of the reported data discrepancies.

Another point deals with the model of ZP-free oocyte that was most frequently used to study gamete interaction $[7,9,21]$. To focus the studies on events that occur at the plasma membrane level, the ZP was removed by chemical, enzymatic or mechanical methods. Indeed, this model prevents any interference between both gamete membranes and is considered to be more convenient for studying their interaction. However, ZP removal dramatically modifies the local conditions of gamete interaction and may also explain some contradictory results that have been previously reported. We recently showed that upon ZP removal, several integrin subunits, including $\alpha 6$, and tetraspanins are relocated and clustered into patches [6]. Simultaneously, several oocyte functions related to fusion are modified. Hence, in human oocyte, the mAb anti-CD9 is effective in inhibiting gamete fusion only if it is introduced in the medium before zona removal and not after [6], suggesting that CD9 tetraspanin function is bypassed by this membrane remodeling. In this study, we now demonstrate the expression of $\alpha 6$ and $\beta 1$ integrin subunits by mouse sperm. We performed IVF assay after preincubation of sperm and/or oocyte with antibodies. Experiments were performed using both acid Tyrode (AT) ZP-free and cumulus-intact oocytes. Thus, we demonstrated that mouse sperm express $\alpha 6 \beta 1$ integrin and that this integrin is involved in the sperm-oocyte interaction process.

\section{Results \\ Alphab and betal integrin subunits are expressed on mouse sperm membrane}

Western blot analysis

Expression of $\alpha 6$ integrin subunit on cauda epididymal sperm was evaluated by immunoblot analysis. As shown on figure $1 \mathrm{~A}$, a specific band at $120 \mathrm{kDa}$, the expected molecular weight of $\alpha 6$ integrin subunit under reducing conditions, was detected on sperm (lane 2: 1 million and lane 3: 2 millions of sperm) and on F9 Whole Cell Lysate (lane 1: $50 \mu \mathrm{g}$ proteins), serving as positive control. The control using a non-specific rabbit polyclonal antibody was negative. The specificity of this result has been confirmed using another antibody raised against $\alpha 6$ integrin subunit and its specific blocking peptide. As illustrated in figure $1 \mathrm{~B}$, the specific band present at $120 \mathrm{kDa}$ with the anti- $\alpha 6$ integrin antibody (lane 1) has disappeared when the anti- $\alpha 6$ integrin antibody was preincubated with its specific blocking peptide (lane 2). These results demonstrated the expression of $\alpha 6$ integrin subunit on sperm. 


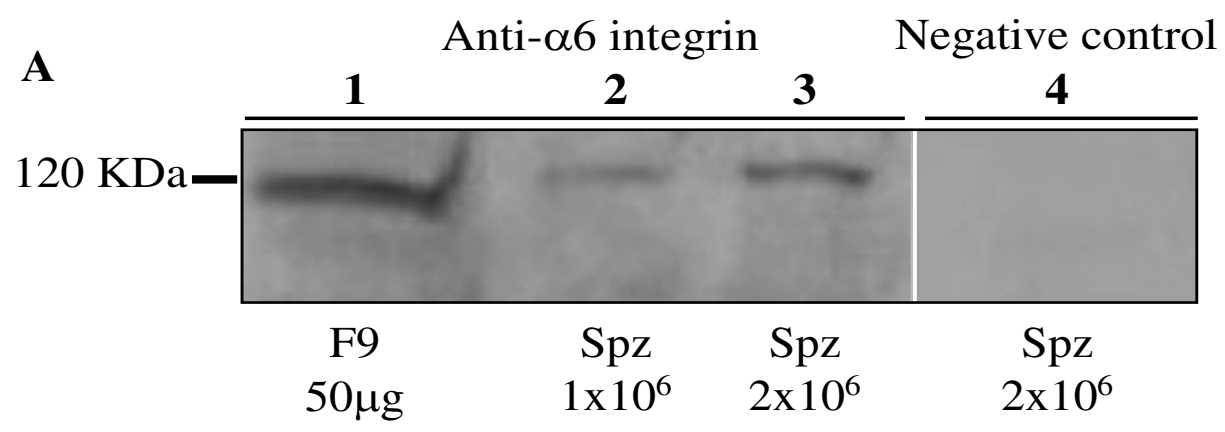

B

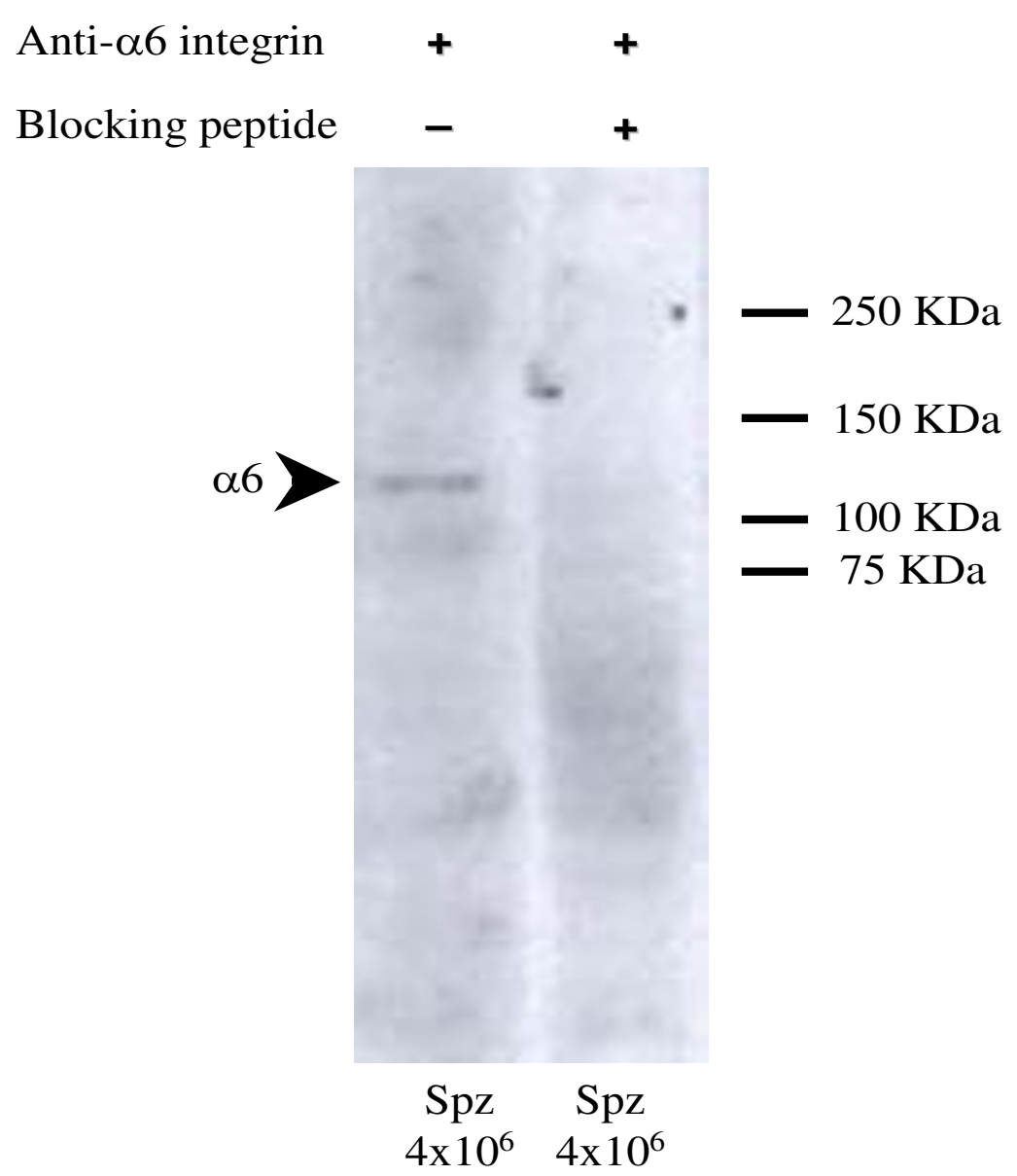

\section{Figure I}

Expression of alpha6betal integrin on mouse sperm. Alpha 6 integrin subunit expression was investigated by Western blot analysis. Proteins from epididymal sperm were extracted with $1 \%$ NP40, subjected to SDS-PAGE under reducing conditions and blotted with two different anti- $\alpha 6$ integrin antibodies to reinforce the specificity of the detection. A: I20 kDa specific band was detected on sperm extracts after rabbit polyclonal antibody incubation $(\mathrm{H}-87$ at $0,2 \mu \mathrm{g} / \mathrm{ml})$, (lanes 2 and 3 : I and 2 millions of sperm, respectively). This band corresponds to $\alpha 6$ integrin subunit as confirmed by the use of the F9 Whole Cell Lysate as positive control (lane I: $50 \mu \mathrm{g}$ of proteins). No specific band appeared when a non specific rabbit lgG was used (lane 4). B: Using the $\mathrm{N}-19$, goat polyclonal antibody rose against a peptide mapping at $\mathrm{N}$-terminus of $\alpha 6$ integrin subunit, a similar band was detected (lane I). This band disappeared when the blocking peptide was added (lane 2). 


\section{Immunofluorescence analysis}

Immunofluorescence analysis of mouse sperm was carried out with anti- $\alpha 6$ and anti- $\beta 1$ integrin antibodies (GoH3 and MB1.2, respectively). In parallel, acrosomal status was assessed by Pisum sativum agglutinin (PSA) staining protocol. Data revealed different distribution patterns of the integrin subunits on the sperm membrane as shown in figure 2. Freshly recovered non capacitated sperm did not show any distinct fluorescence (Fig. 2c). After 90 minutes under capacitating conditions, more than $70 \%$ of sperm presented integrin molecules on their membranes organized in various patterns: dense fluorescent dots of the equatorial region of non acrosome reacted (AR) capacitated sperm (40\%; Fig. 2f) or AR sperm (50\%; Fig. 2i) and an exclusive distribution in the post acrosomal region of AR sperm (10\%; Fig. 2l). Control isotype or secondary antibody alone gave no signal (data not shown). Similar distribution, staining and relative proportions were found for $\beta 1$ integrin subunit (Fig. $2 e^{\prime} h^{\prime} k^{\prime}$ ).

\section{Flow cytometry analysis}

Presence of $\alpha 6$ and $\beta 1$ integrin subunits on capacitated mouse sperm was confirmed afterwards by flow cytometry after indirect immunofluorescence staining. Capacitated spermatozoa labeled with anti- $\alpha 6$ (Fig. $3 \mathrm{~A}$ ) and anti- $\beta 1$ antibodies (Fig. 3B) were distributed in single peaks with a mean fluorescence intensity of 21 and 34 versus 5 and 8 for control isotype, respectively. Freshly recovered non capacitated sperm was not stained (data not shown).

\section{Effects of antibodies against alphab and betal integrin subunits on mouse sperm-egg fusion}

Since the presence of $\alpha 6$ and $\beta 1$ integrin subunits on mouse sperm was demonstrated, we next investigated their involvement during fertilization. We evaluated, in the presence or in the absence of antibodies, the percentage of fertilized eggs (FR) in both cumulus-intact and acid Tyrode (AT) zona-free egg assays and the average number of sperm fused per egg (fertilization index: FI) in AT zonafree egg assays. As these integrin subunits are also expressed by the oocytes [7], we determined to what extent each gamete is involved in the inhibition process. Different groups were studied. The group 1 was the control IVF. In groups 2 and 3, only one of the two gametes (oocytes or sperm, respectively) was preincubated with function-blocking antibodies, washed and inseminated without antibodies. In group 4, both gametes were separately preincubated with the function-blocking antibodies, washed and then inseminated without any antibody as in previous groups. In group 5, oocytes were inseminated in presence of antibodies without any preincubation. In groups 6,7 and 8 , anti- $\beta 1$ antibody was present during the insemination while oocytes, sperm or both had been preincubated with it. Results differed according to the presence or the absence of ZP. When experiments were
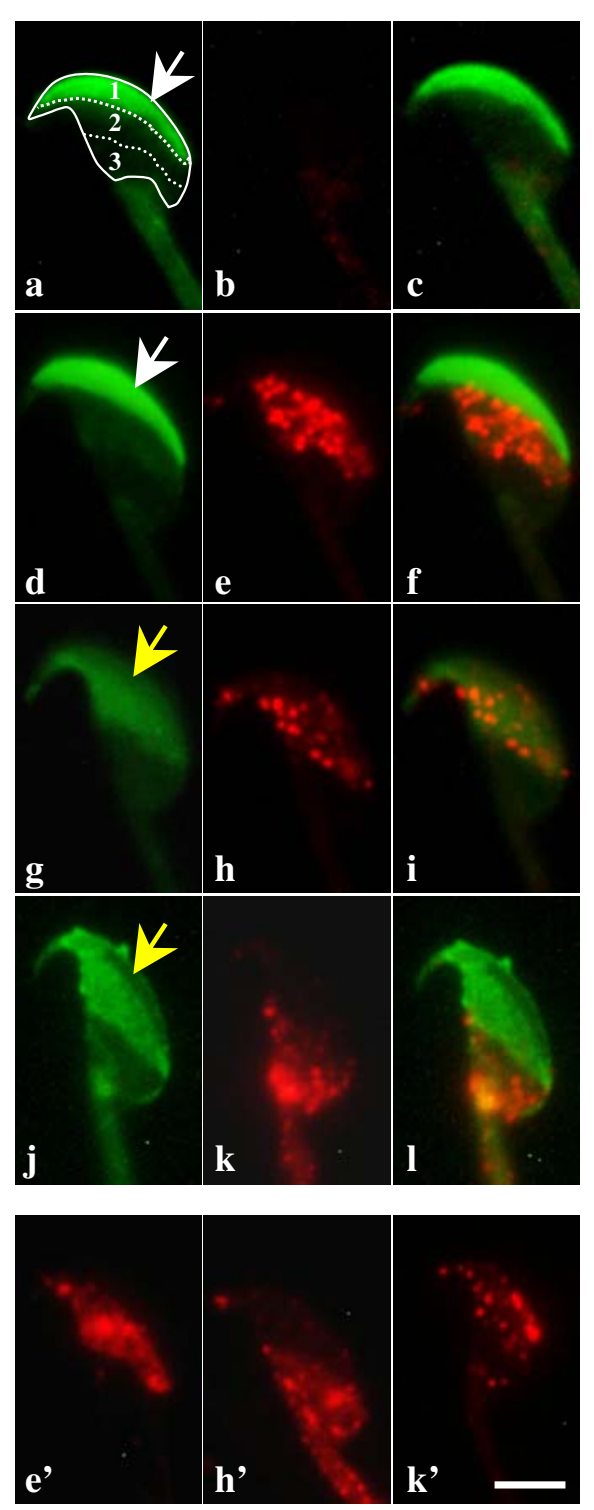

\section{Figure 2}

Expression and distribution of alphabbetal integrin on mouse sperm. Distribution of $\alpha 6 \beta$ I integrin was studied by immunofluorescence microscopy. Spermatozoa were exposed to FITC-PSA ( $a, d, g, j)$ after anti- $\alpha 6$ integrin $\mathrm{GoH} 3$ antibody (b, e, h, k) or anti- $\beta$ I integrin MBI. 2 antibody (e', h', k') followed by Alexa Fluor ${ }^{\circledR} 594$ (red) goat anti-rat lgG secondary antibody. The following fluorescent patterns were recorded: negative non capacitated sperm (b), equatorial localization on capacitated sperm (e, e', h, h') and post-acrosomal localization ( $\left.k, k^{\prime}\right)$ only on capacitated AR sperm. c, f, i and I represent composite images generated by superimposition of the green and red signals. Arrows indicate the position of intact (white) or reacted (yellow) acrosome. In order to distinguish the different spermatic regions, they were delimited on the image (a); I: acrosome, 2: equatorial region and 3: post-acrosomal region. Bar $=5 \mu \mathrm{m}$. 


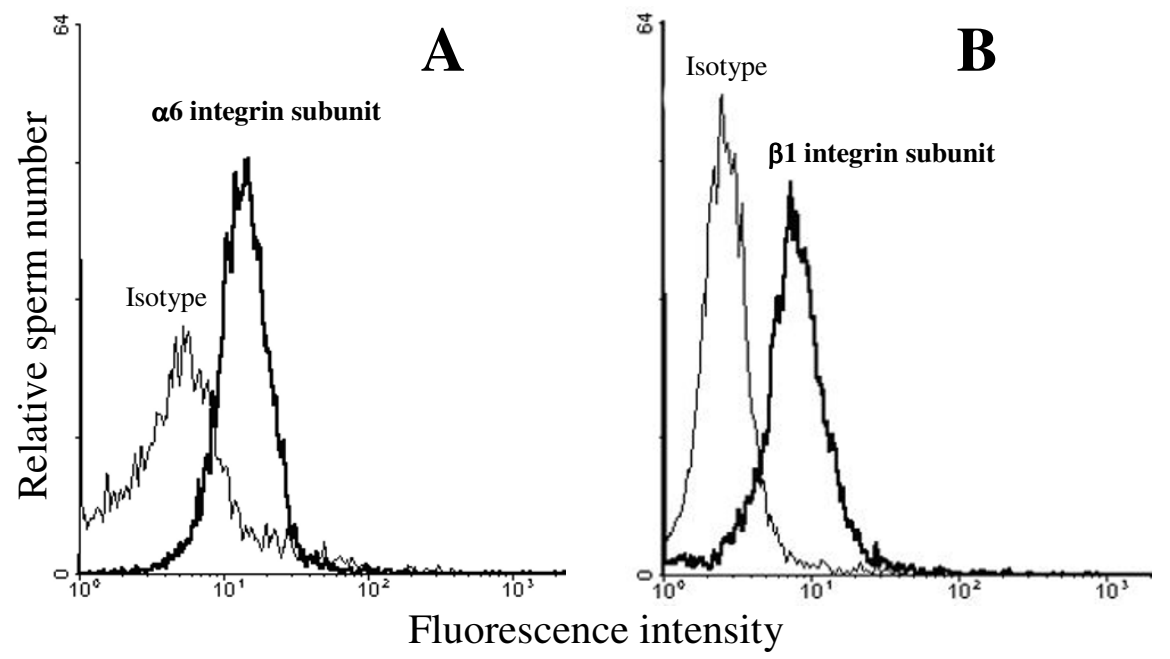

\section{Figure 3}

Flow cytometric analysis of alpha6betal integrin expression on mouse sperm. Expression of $\alpha 6$ and $\beta$ I integrin subunits on capacitated mouse sperm was evaluated by flow cytometry. Sperm cells were incubated with the mAb anti- $\alpha 6$ $(\mathrm{GoH} 3)(\mathbf{A})$ or anti- $\beta$ I (MBI.2) (B) or Rat lgG2a isotype negative control (A, B), stained with Alexa Fluor ${ }^{\circledR} 594$ (red) goat antirat IgG, then analyzed by flow cytometry on the basis of FSC/FLI (cell size/relative fluorescence) parameters.

performed with isotype (rat IgG2a) or with medium containing sodium azide at $0,02 \%$ final concentration as controls, no inhibition was detected (data not shown). It is important to note that none of the function blocking antibody used altered the sperm motility.

Effect of $\mathrm{GoH} 3$ on cumulus-intact egg insemination (Table I) Control FR was $91 \% \pm 3$. Our protocols of selective preincubation of each gamete allowed us to discriminate between GoH3 effects on oocytes and sperm respectively. When oocytes (group 2) and sperm (group 3) were preincubated with GoH3, the FR was reduced by $26 \%(68 \%$ versus $91 \%$; $\mathrm{P}<0.0002$ ) or $45 \%$ (50\% versus $91 \%$; $\mathrm{P}<$ $0.0001)$, respectively. GoH3 was even more potent in inhibiting sperm than oocyte functions $(P<0.03)$. When both gametes were preincubated (group 4), the FR inhibition was $65 \%$ (31\% versus $91 \%$; $\mathrm{P}<0.0001$ ) corresponding to the additive effect of $\mathrm{GoH} 3$ on each gamete. The three hours of cumulus-intact oocytes insemination with GoH3 and without any preincubation (group 5) gave nearly a $90 \%$ inhibition of the FR, compared to the control (10\% versus 91\%; $\mathrm{P}<0.0001)$. This inhibition was stronger $(\mathrm{P}<0.003)$ than that recorded after preincubation of both gametes with the antibody. This could be explained by the inhibition of lately recruited GoH3 binding sites during the incubation.
Effect of $\mathrm{GOH} 3$ on acid Tyrode zona-free egg insemination (Table I) In all groups of AT zona-free egg assay, membrane gamete interaction is immediate. Because of this extremely rapid process, all eggs were fertilized (FR $=100 \%)$. GoH3 mAb had no effect on AT zona-free oocytes since the FI of group 2 was not modified when compared to the control group, showing that ZP removal by AT renders oocytes insensitive to GoH3 effects. Only sperm preincubation (group 3) with GoH3 significantly reduced the FI. Interestingly, if both gametes were inseminated in presence of GoH3, without preincubation (group 5), the FI was not reduced. In contrast, if the same experiment was performed with cumulus-intact eggs, an almost complete inhibition was observed. Therefore: 1) the AT zona removal induced a disappearance of the GoH3 effects on the oocytes, 2) sperm GoH3 effect is not immediate and requires a delay to be effective. This explains that sperm preincubation inhibits ZP-intact but not AT-ZP-free oocytes fertilization and suggests that the time to get through the ZP could be a necessary delay for sperm inhibition to appear.

Cumulus-intact and acid Tyrode zona-free egg assays with anti-beta I integrin subunit antibody (Table I)

Gamete preincubation with anti- $\beta 1 \mathrm{mAb}$ (L16), both in cumulus-intact and AT ZP-free assays, had no effect (groups 2 to 4 , data not shown) while the presence of the antibody during insemination impaired gamete interaction (groups 5-8) and was not modified by any preincu- 
Table I: Effects of alpha6 and betal integrin subunits antibodies on sperm-egg fusion

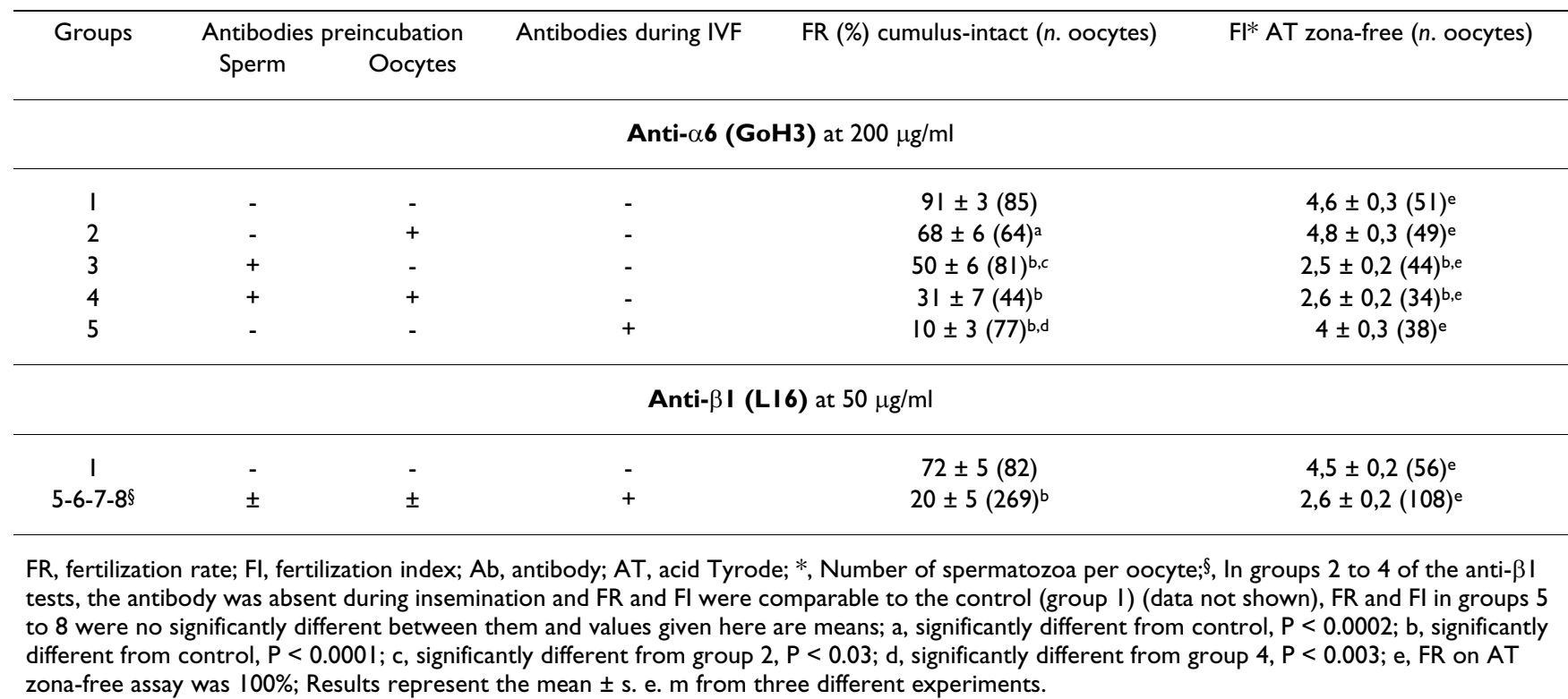

bation. In cumulus-intact eggs assay, in presence of antiintegrin subunit $\beta 1 \mathrm{mAb}$, the FR was significantly decreased by approximately $70 \%(\mathrm{P}<0.0001)$, compared to the control group. In AT zona-free egg assays, all inseminated oocytes were fertilized ( $F R=100 \%)$, but a significant reduction in the FI (approximately 50\%, P < 0.0001) was obtained in all groups.

\section{Zona pellucida removal modifies alpha6 and beta I integrin subunits distribution}

In an attempt to explain the lack of anti- $\alpha 6$ antibody effect on AT zona-free oocytes, we studied the localization of $\alpha 6 \beta 1$ integrin on zona-intact and AT zona-free eggs by immunofluorescence and confocal microscopy analysis. About 90 optical sections, representing nearly half of the eggs, were collected and superimposed using the maximum projection function as shown on figure 4 . Whereas the $\alpha 6$ and $\beta 1$ integrin subunits were distributed homogeneously with fine punctuations around the egg surface of zona-intact oocytes (Fig. $4 \mathrm{e}$ and $4 \mathrm{~g}$ ), ZP removal resulted in a modification of the alpha6 and beta 1 integrin subunits distribution. Indeed, both formed patches on the AT zona-free oocyte membrane (Fig. $4 \mathrm{f}$ and $4 \mathrm{~h}$ ). This integrin redistribution induced upon AT ZP removal seems to put the oocyte at a stage in which integrins are no longer required for adhesion/fusion, explaining in turn the absence of anti- $\alpha 6$ antibody effect on AT zona-free oocytes during fertilization.

\section{Discussion}

Here, we show that the $\alpha 6 \beta 1$ integrin is expressed on mouse sperm and is functionally involved in the spermoocyte interaction process. These data reinforce the role of $\alpha 6 \beta 1$ integrin in the process of gamete interaction $[6,7]$.
We also confirm that AT-ZP removal bypasses the $\alpha 6 \beta 1$ integrin function in mouse oocyte at the time of gamete interaction.

We show that mouse sperm express $\alpha 6 \beta 1$ integrin by western blot analysis, flow cytometry and immunofluorescence confocal microscopy. This last technique enables to localize the $\alpha 6 \beta 1$ integrin on the surface of capacitated and capacitated and AR spermatozoa. Alpha6beta1 integrin clusterisation at the surface of the spermatozoon head in a dotty pattern suggests its activation. As the fertilizing spermatozoon normally present in the perivitelline space is $A R$, is more likely to present this staining pattern. As the fusion starts at the equatorial and post acrosomal region [22], this localization of the $\alpha 6 \beta 1$ sperm integrin reinforces its probable implication in the adhesion/fusion process.

Our results are different from those of other groups $[7,23]$. In our study, when zona pellucida was totally removed by acid Tyrode, oocytes were insensitive to GoH3 effect. Consequently, we observed gamete interaction inhibition only when sperm was preincubated with GoH3, while Almeida et al. reported a total inhibition by GoH3 (after oocyte preincubation) of oocyte-sperm binding and therefore of fusion [7]. This inhibition could have been due to GoH3 effect on both oocyte and sperm. Indeed, in these experiments, very brief chymotrypsin treatment was used and may not have completely removed the zona pellucida [24]. Hence, oocytes were probably not totally insensitive to GoH3 effect. Furthermore, in their experiment, GoH3 have not been washed out from oocyte preincubation medium before sperm addition, contrary to what we did. Therefore, the delay necessary for the sper- 

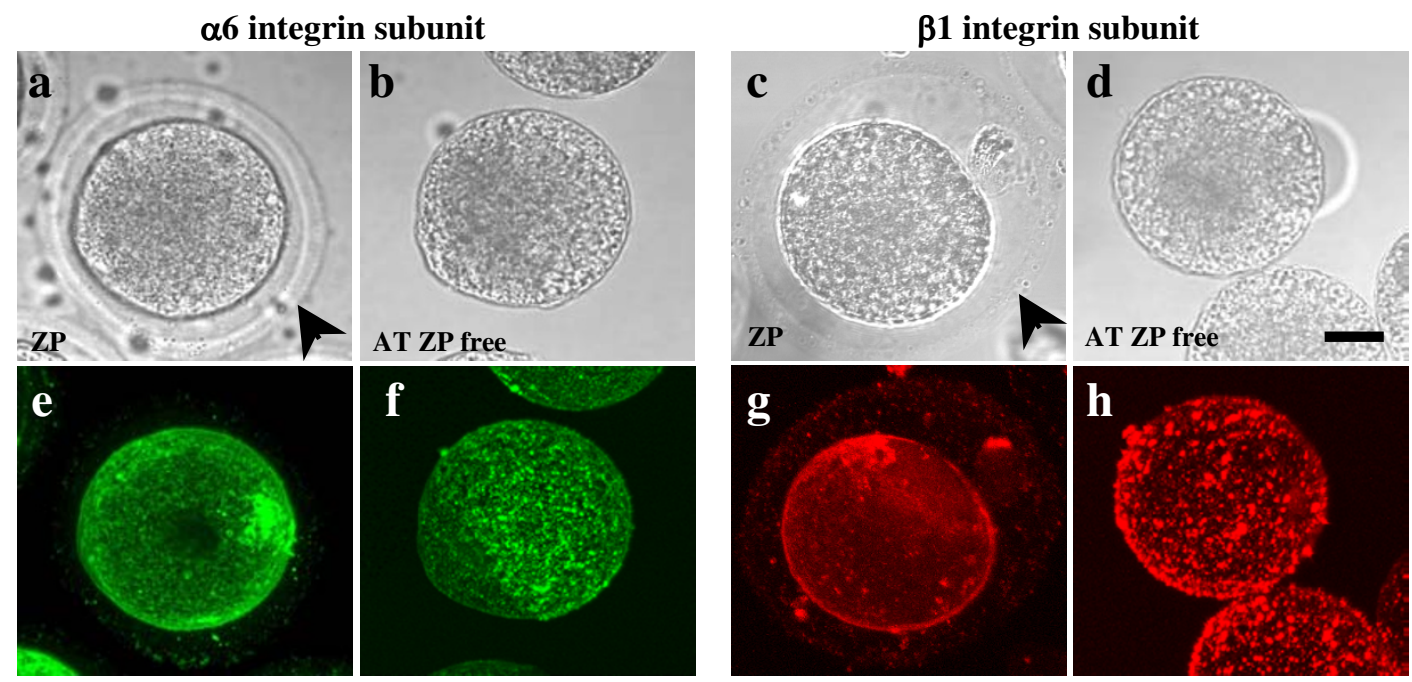

\section{Figure 4}

Acid Tyrode's zona removal modifies distribution of alpha6 and betal integrin subunits on mouse oocytes. Zona-intact or acid Tyrode ZP-free mouse oocytes were incubated with anti- $\alpha 6$ integrin GoH3 (e, f) or anti- $\beta$ I integrin MBI.2 antibodies (g, h), then with Alexa Fluor ${ }^{\circledR} 488$ (green) or 594 (red) goat anti-rat IgG respectively and analyzed by confocal microscopy as described in Material and methods. These molecules were distributed homogeneously with fine punctuations around the surface of the zona-intact oocytes $(e, g)$, but both formed patches on the acid Tyrode zona-free oocyte surface (f, h). About 90 sections, representing nearly half of the eggs were collected. The maximum projection function was then used to superimpose the different sections. Transmission images corresponding to each oocyte are shown $(a, b, c, a n d d)$. Bar $=20 \mu m$.

matozoon to get through the zona pellucida may have stood for the time of GoH3 sperm preincubation. Actually, these experimental conditions were closer to our cumulus-intact IVF ones, accounting for similar results in apparently different IVF conditions. In our previous study, we probably also misinterpreted the GoH3 effect on the human IVF by allotting it exclusively to the oocyte integrin [6]. This effect may have mainly been mediated by the spermatic one.

Two previous studies, using zona-intact or cumulus-intact eggs assays, reported GoH3 lack of inhibition on gamete fusion $[11,23]$. In the first one, the IVF test was run in small volumes $(10 \mu \mathrm{l})$. As stated in the report itself, it is known that IVF is inefficient in these conditions (Control $\mathrm{FR}=30 \%$ ). This might have hidden the GoH3 inhibition effect. In the second experiment, contrary to the 3 hours incubation commonly used and as used in our study, insemination lasted 24 hours. Therefore, the evaluation of the FR was not performed according to the presence of decondensed sperm head within the ooplasm, but to the two cell stage criteria. This is not the usual criterion to evaluate fertilization per se, but that of egg activation which can also be achieved by parthenogenetic process.
The most frequent argument to rule out the possible role of $\alpha 6 \beta 1$ integrin in gamete interaction is the fertility of $\alpha 6$ or $\beta 1$ integrin subunits deleted mice oocytes $[11,13]$. However, all the experiments performed with deleted oocytes, including mating, used wild-type spermatozoa. According to our present results which show the presence of the $\alpha 6 \beta 1$ integrin on sperm, these spermatozoa carried the $\alpha 6$ and $\beta 1$ integrin subunits that had been deleted on the oocyte. This means that, prior to fusion, at the gamete membrane merge, these molecules were present. We therefore have to hypothesize that the presence of this integrin on one of the two fusing membranes is sufficient for fusion. Such hypothesis is supported by the sperm oocyte membrane exchange occurring prior to fusion we reported recently [25]. In this work, we have shown that CD9 tetraspanin is transferred with the exchanged membrane fragment from oocyte to sperm. One can hypothesize that sperm $\alpha 6 \beta 1$ integrin could transfer too and, therefore, may have rescued adhesion and fusion in deleted oocytes. The way to definitively answer the question of the implication of $\alpha 6 \beta 1$ integrin in gamete interaction during fertilization is the deletion of $\alpha 6$ and/or $\beta 1$ integrin gene in both gametes. This part of study is under current evaluation. 
In our study, AT zona-free eggs were all fertilized whatever the anti- $\alpha 6$ or anti- $\beta 1$ integrin subunits antibodies used. This could be explained by the direct free access for sperm to oocyte membrane, preventing the effect of the antibody on the sperm. But, importantly, the FI was not affected even when oocytes were preincubated with GoH3 showing that they had become insensitive to its effects. Thus, the oocyte $\alpha 6 \beta 1$ integrin is in such a situation that it is no longer needed. As fusion still occurs, we have to conclude that it had been bypassed by the AT ZP removal. This is another reason for the FR being poorly affected by GoH3 on AT ZP-free eggs. Similar bypasses have already been described in human eggs upon mechanical ZP removal [6]. When mouse intact $C d 9 \%$ eggs are inseminated, spermatozoa swim into the perivitelline space without binding to the oolemma. On the contrary, large amounts of spermatozoa tightly bind to the oolemma of AT zona-free Cd9-/- mouse eggs [4].

To investigate this hypothesis, we studied $\alpha 6$ and $\beta 1$ integrin subunits distribution on ZP-intact and AT ZP-free oocytes. $\alpha 6$ and $\beta 1$ integrin subunits were evenly distributed on the surface of zona-intact mouse eggs (Fig. 4e,g). On the oocyte surface of AT ZP-free eggs, these integrins were detected as well, but in larger regularly arranged patches (Fig. 4f,h). The same relocation had been observed in human egg upon ZP removal [6]. We also have reported a relocation of the $\alpha 6$ integrin subunit upon fertilization of mouse zona-intact eggs [6] suggesting that the two phenomena are linked. We can then hypothesize that fertilization and $\alpha 6 \beta 1$ integrin redistribution are physiologically linked. Once this relocation has happened, $\alpha 6 \beta 1$ integrin has less or no function in the process of gamete binding and fusion. This means that anti- $\alpha 6$ antibodies have few or no effect on AT ZP-free mouse oocytes. For all these reasons and also because is closer to what the physiology should be, experiments using zona-intact eggs have to be preferred to the zonafree oocytes ones.

Takahashi reported an $\alpha 6 \beta 1$ integrin clustering at the point of gamete contact on ZP-free oocyte [9]. The presence of $\alpha 6 \beta 1$ integrin on the capacitated and AR sperm suggests another non exclusive interpretation. The cluster of $\alpha 6 \beta 1$ integrin at the point of gamete contact could also be due to the superimposition of oocyte and sperm $\alpha 6 \beta 1$ integrin detection. The fact that $\alpha 6 \beta 1$ is not detectable on the surface of fresh sperm may explain why clusterisation was not reported when using non capacitated sperm [9]. In our study, the fertilizing index of AT ZP-free oocytes was reduced only when sperm had been preincubated with GoH3, supporting the existence of a direct effect of this antibody on sperm functions.

\section{Conclusion}

The presence of functional $\alpha 6 \beta 1$ integrin on mouse sperm raises the question about the role of this integrin in gamete interaction. It appears as one piece of a multimolecular binding and fusion complex which should be present on both oocyte and sperm membranes. As it can be bypassed by the oocyte membrane reorganization upon $\mathrm{ZP}$ removal, we can hypothesize that binding of its ligand to oolemma $\alpha 6 \beta 1$ integrin is one of the first steps of gamete membrane interaction process. The only essential molecules that had been recognized so far for sperm-egg binding and fusion are the CD9 tetraspanin on the oocyte [2$4]$ and on the sperm membrane, the Izumo immunoglobulin [1], which are up to date the unique unilaterally distributed molecules. It could be interesting to study its relation to the sperm $\alpha 6 \beta 1$ integrin. A similar interest should be granted to the integrin potential ligands on the sperm.

\section{Methods \\ Antibodies}

The function blocking rat mAbs against the integrin $\alpha 6$ (GoH3) or polyclonal goat anti- $\beta 1$ integrin (L16) subunits were purchased from R\&D Systems (France) and Santa Cruz Biotechnology (USA) respectively. For immunofluorescence studies, the rat mAb anti-mouse $\beta 1$ integrin (clone MB1.2) came from Chemicon International (USA). Secondary antibodies used in immunocytochemistry and flow cytometry experiments were Alexa Fluor $^{\circledast} 488$ (green) or 594 (red) goat anti-rat IgG from Molecular Probes (Invitrogen, France). Rat IgG2a isotype (Serotec, France) was used as negative control. Vectashield mounting medium supplemented with DAPI and FITCPSA were purchased from Vector Laboratories (USA). For Western blot analysis, the rabbit polyclonal antibody raised against the C-terminus of mouse integrin $\alpha 6(\mathrm{H}-$ 87 ), the goat polyclonal antibody rose against a peptide mapping at N-terminus of integrin $\alpha 6(\mathrm{~N}-19)$ and the specific blocking peptide of N-19 antibody were from Santa Cruz Biotechnology. The non-specific rabbit polyclonal antibody and the biotinylated goat anti-rabbit IgG were from Vector Laboratories; the polyclonal rabbit anti-goat HRP-conjugated was from DakoCytomation (Denmark); the streptavidin HRP-conjugated was from Immunotech (France).

\section{Gamete preparation and in vitro fertilization}

Cumulus-intact or acid Tyrode zona-free oocyte preparation

B6CBA F1 female mice (5-8 weeks old) purchased from Charles River Laboratories (France) were superovulated with 5 IU PMSG and 5 IU hCG (Intervet, France) 48 hours apart. Twelve to 14 hours after hCG injection, the animals were sacrificed by cervical dislocation. Cumulus oophorus were collected by tearing the ampulla wall of the oviduct and placed in Whittingham's medium [26] with 3\% BSA 
(Sigma) at $37^{\circ} \mathrm{C}$ under $5 \% \mathrm{CO}_{2}$ in air under mineral oil (Sigma). When needed cumulus cells were removed by a brief exposure to hyaluronidase (Sigma) $(0.01 \%)$. The ZP was then dissolved with acidic Tyrode's (AT) solution ( $\mathrm{pH}$ 2.5) (Sigma) under visual monitoring. The AT zona-free eggs were rapidly washed five times and directly fixed, or kept at $37^{\circ} \mathrm{C}$ under $5 \% \mathrm{CO}_{2}$ in air for 3 hours to recover their fertilization ability.

\section{Sperm preparation}

Mouse spermatozoa were obtained from the caudae epididymis of B6CBA F1 mice (8 to 13-week-old) and capacitated at $37^{\circ} \mathrm{C}$ for 90 minutes in a $500 \mu \mathrm{l}$ drop of Whittingham's medium supplemented with $30 \mathrm{mg} / \mathrm{ml}$ BSA, under mineral oil.

\section{In vitro fertilization}

Cumulus-intact or AT zona-free eggs were inseminated with capacitated spermatozoa for 3 hours in a $100 \mu$ drop of medium. Then, they were washed and directly mounted in Vectashield/DAPI for observation under UV light (Zeiss Axioskop 20 microscope). Were considered fertilized, the oocyte showing fluorescent decondensed sperm head within their cytoplasm. To assess the FI, the number of decondensed sperm head was recorded.

To test the effect of antibodies on the FR and FI, one or both gametes were separately preincubated for $30 \mathrm{~min}$ utes in medium supplemented with $\mathrm{GoH} 3$ at $200 \mu \mathrm{g} / \mathrm{ml}$ or L16 at $50 \mu \mathrm{g} / \mathrm{ml}$ prior to IVF. Oocytes were then washed and sperm were diluted 1:100 into the final droplet containing the oocytes. To test fusion, oocytes were inseminated at a final sperm concentration of $10^{5} / \mathrm{ml}$ for AT zona-free egg assay and $10^{6} / \mathrm{ml}$ for cumulus-intact egg assay in a new drop of Whittingham's medium $+3 \%$ BSA with or without the antibody.

\section{Sperm Immunolabeling and Fluorescence Microscopy}

Freshly recovered or capacitated spermatozoa were washed in PBS containing 1\% BSA, centrifuged at $600 \mathrm{~g}$ for 5 minutes and immediately fixed in 4\% PFA in PBS$1 \%$ BSA at $4{ }^{\circ} \mathrm{C}$ for 1 hour. After washing, the fixed spermatozoa were incubated in PBS with $20 \mu \mathrm{g} / \mathrm{ml}$ of rat anti$\alpha 6$ or anti- $\beta 1$ integrin subunits antibodies $(\mathrm{GoH} 3$ and MB1.2, respectively) for 1 hour and then with $10 \mu \mathrm{g} / \mathrm{ml}$ of Alexa Fluor 594 (red) goat anti-rat IgG for 1 hour. Control immunofluorescent studies were performed using isotype $\left(\operatorname{IgG}_{2 \mathrm{a}}\right)$ as primary antibody or Alexa Fluor ${ }^{\circledast} 594$ goat anti-rat IgG alone.

Alexa Fluor ${ }^{\circledR} 54$ labeled cells were submitted to the PSAstaining protocol for the sequential detection of integrin distribution and acrosomal status. Spermatozoa were treated for 30 minutes in $95 \%$ ethanol at $4{ }^{\circ} \mathrm{C}$, washed by centrifugation through PBS and stained with FITC-conju- gated lectin PSA ( $25 \mu \mathrm{g} / \mathrm{ml}$ in PBS) for 10 minutes. After repeated washing with double distilled water, a drop of sperm suspension was smeared on slide, air-dried, mounted with Vectashield/DAPI and covered with a coverslip for analysis. Detection was performed using a Zeiss Axiophot epifluorescence microscope and images were digitally acquired with a camera (Coolpix 4500, Nikon).

\section{Flow cytometry analysis of alphab and betal integrin subunits on mouse spermatozoa}

Freshly recovered and capacitated sperm surface expression of $\alpha 6$ and $\beta 1$ integrin subunits were evaluated using a FACScan flow cytometer (Becton Dickinson, San Jose, CA, USA) equipped with argon laser (power: $15 \mathrm{~mW}$, wavelength: $488 \mathrm{~nm}$ ). Flow cytometer was driven with the Cellquest software (Becton Dickinson). The staining procedure was the same as that used for immunofluorescence. Finally, sperm was kept in 1\% PFA in PBS at $10^{6}$ sperm $/ \mathrm{ml}$. For each sample, 5,000 cells were analyzed at a flow rate of 200-300 cells per second using FSC/FL1 (cell size/relative fluorescence) parameters. The fluorescence data were collected using the logarithmic amplifier. Autofluorescence of the sample was measured using sperm that were never exposed to antibodies and negative controls were performed with the isotype and second antibody or second antibody alone.

\section{Confocal analysis of indirect immunofluorescence oocyte staining}

Immunodetection of the integrin subunits was carried out on ZP-intact and AT zona-free eggs. Oocytes were fixed in $2 \%$ PFA diluted in PBS-1\% BSA for 20 minutes. For detection of the $\alpha 6$ or $\beta 1$ integrin subunits, oocytes were incubated with the primary antibody GoH3 or MB1.2 $(20 \mu \mathrm{g} /$ $\mathrm{ml}$ each one) for 1 hour at room temperature (RT) and then with the suitable secondary antibodies for 1 hour at RT. Controls were prepared by replacing primary antibody by rat IgG2a isotype.

Oocytes were mounted in PBS $1 \times$ in Lab-Tek ${ }^{\circledast}$ chambers (Nalge Nunc International, Naperville, USA) and images were captured using a Leica TCS SP2 AOBS confocal microscope. Ninety oocytes sections were collected. The maximum projection function was then used to superimpose the different sections. Image analysis was performed using ImageJ free-software [27].

\section{Western Blot analysis}

Capacitated sperm were washed twice in PBS, the pellet snap-frozen in liquid $\mathrm{N} 2$ and stored at $-80^{\circ} \mathrm{C}$ for further use. Sperm aliquots were lysed in $50 \mathrm{mM}$ Tris (pH 8), 150 $\mathrm{mM} \mathrm{Nacl}, 1 \mathrm{mM}$ EDTA, 0,25\% sodium desoxycholate and $1 \%$ NP40, supplemented with Protease Inhibitor Cocktail (Sigma) for 1 hour on ice, boiled for 5 minutes with an equal volume of $2 \times$ NuPAGE $^{\circledast}$ LDS sample buffer (Invitro- 
gen, France) supplemented with 5\% $\beta$-mercaptoethanol. Semen lysate was gently sonicated. F9 Whole Cell Lysate (Abcam, France) was used as a positive control for the $\alpha 6$ integrin subunit detection. Sample proteins were separated by 4 to $20 \%$ SDS-Polyacrilamide gel electrophoresis (Euromedex, France) and electro-transferred to Immobilon-P membranes (Millipore, France). Membranes were blocked overnight with Western Blocking Reagent (Roche, France) prior incubation with appropriate primary antibodies (Rabbit anti- $\alpha 6$ integrin: 0,2 $\mu \mathrm{g} / \mathrm{ml}$, non-specific rabbit IgG: $0,2 \mu \mathrm{g} / \mathrm{ml}$ ) for 90 minutes at $37^{\circ} \mathrm{C}$ followed by biotinylated appropriate secondary antibodies (biotinylated anti-rabbit: $0,2 \mu \mathrm{g} / \mathrm{ml}$ ) and HRP-Streptavidin $(0,02 \mu \mathrm{g} / \mathrm{ml})$, each for 1 hour at $37^{\circ} \mathrm{C}$. For competition study between anti- $\alpha 6$ integrin antibody (N-19) and its specific blocking peptide, a mixing of equal volume of each of them was prepared and incubated at $4{ }^{\circ} \mathrm{C}$ overnight. The day after, membranes were incubated with either this mixing or with the anti- $\alpha 6$ integrin antibody (N-19) alone at the dilution $1 / 200(1 \mu \mathrm{g} / \mathrm{ml})$, overnight at $4^{\circ} \mathrm{C}$; the membranes were then kept 1 hour at $37^{\circ} \mathrm{C}$ before an incubation with the secondary rabbit anti-goat antibody HRP-conjugated (1/2000) for 1 hour at RT. HRP activity was revealed by ECL detection kit (Amersham Biosciences, UK) and autoradiography (BioMax Light Film, Kodac). Film exposure was less than 5 minutes.

\section{Statistical analysis}

Statistical analysis was performed using Statview ${ }^{\circledast}$ package. Means were compared by non-paired t test. Differences were considered significant at $P<0.05$.

\section{Abbreviations}

AR- Acrosome reacted.

AT- Acid Tyrode.

FI- Fertilization index.

FR- Fertilization rate.

IVF- In vitro fertilization.

PSA- Pisum sativum agglutinin.

RT- Room temperature.

ZP- Zona pellucida.

\section{Authors' contributions}

VB-L participated in the design of the study, Western blot analysis, confocal analysis and helped to draft the manuscript. NN-B carried out the sperm immunolabeling and fluorescence microscopy and participated to oocytes confocal analysis. LS and LG carried out the flow cytometry analysis. BD performed the statistical analysis. ASD participated in the Western blot analysis. MB participated in the design of the study, the Western blot analysis and redaction of the manuscript. JPW participated in the design of the study and redaction of the manuscript. AZ conceived and coordinated the study, drafted the manuscript, carried out the gamete preparation and in vitro fertilization assays. All authors read and approved the final manuscript.

\section{Acknowledgements}

We thank S. Chambris (Université Paris 13) for his technical assistance, P. Bourdoncle for confocal analysis, A. Benkhelifa, L. Dandolo and D.

Montjean for editorial assistance and the authors of the plugins of ImageJ freeware. This work was supported by grants from Organon (subvention FARO), Association Jacques Salat-Baroux and the Société d'Andrologie de Langue Française (SALF).

\section{References}

I. Inoue N, Ikawa M, Isotani A, Okabe M: The immunoglobulin superfamily protein Izumo is required for sperm to fuse with eggs. Nature 2005, 434:234-238.

2. Kaji K, Oda S, Shikano T, Ohnuki T, Uematsu Y, Sakagami J, Tada N, Miyazaki S, Kudo A: The gamete fusion process is defective in eggs of Cd9-deficient mice. Nat Genet 2000, 24:279-282.

3. Le Naour F, Rubinstein E, Jasmin C, Prenant M, Boucheix C: Severely reduced female fertility in CD9-deficient mice. Science 2000 , 287:319-32I.

4. Miyado K, Yamada G, Yamada S, Hasuwa H, Nakamura Y, Ryu F, Suzuki K, Kosai K, Inoue K, Ogura A, Okabe M, Mekada E: Requirement of CD9 on the egg plasma membrane for fertilization. Science 2000, 287:32I-324.

5. Rubinstein E, Ziyyat A, Prenant M, Wrobel E, Wolf JP, Levy S, Le Naour F, Boucheix C: Reduced fertility of female mice lacking CD8I. Dev Biol 2006, 290:35I-358.

6. Ziyyat A, Rubinstein E, Monier-Gavelle F, Barraud V, Kulski O, Prenant M, Boucheix C, Bomsel M, Wolf JP: CD9 controls the formation of clusters that contain tetraspanins and the integrin \{alpha\}6\{beta\}I, which are involved in human and mouse gamete fusion. J Cell Sci 2006, I 19:4I 6-424.

7. Almeida EA, Huovila AP, Sutherland AE, Stephens LE, Calarco PG, Shaw LM, Mercurio AM, Sonnenberg A, Primakoff P, Myles DG, et al: Mouse egg integrin alpha 6 beta I functions as a sperm receptor. Cell 1995, 8 I:1095-II 04.

8. Chen H, Sampson NS: Mediation of sperm-egg fusion: evidence that mouse egg alpha6betal integrin is the receptor for sperm fertilinbeta. Chem Biol 1999, 6:1-10.

9. Takahashi $Y$, Yamakawa N, Matsumoto K, Toyoda Y, Furukawa K, Sato $E$ : Analysis of the role of egg integrins in sperm-egg binding and fusion. Mol Reprod Dev 2000, 56:4I 2-423.

10. Evans JP, Kopf GS, Schultz RM: Characterization of the binding of recombinant mouse sperm fertilin beta subunit to mouse eggs: evidence for adhesive activity via an egg betal integrinmediated interaction. Dev Biol 1997, 187:79-93.

II. Miller BJ, Georges-Labouesse E, Primakoff P, Myles DG: Normal fertilization occurs with eggs lacking the integrin alpha6betal and is CD9-dependent. J Cell Biol 2000, 149:1289-1296.

12. Evans JP, Schultz RM, Kopf GS: Characterization of the binding of recombinant mouse sperm fertilin alpha subunit to mouse eggs: evidence for function as a cell adhesion molecule in sperm-egg binding. Dev Biol 1997, 187:94-106.

13. He ZY, Brakebusch C, Fassler R, Kreidberg JA, Primakoff P, Myles $D G$ : None of the integrins known to be present on the mouse egg or to be ADAM receptors are essential for sperm-egg binding and fusion. Dev Biol 2003, 254:226-237.

14. Glander HJ, Schaller J: Beta I-integrins of spermatozoa: a flow cytophotometric analysis. Int J Androl 1993, 16(2): I05-III.

15. Schaller J, Glander HJ, Dethloff J: Evidence of beta I integrins and fibronectin on spermatogenic cells in human testis. Hum Reprod 1993, 8(II): 1873-1878. 
16. Reddy VR, Rajeev SK, Gupta V: Alpha 6 beta I Integrin is a potential clinical marker for evaluating sperm quality in men. Fertil Steril 2003, 79(Suppl 3): 1590-1596.

17. Klentzeris LD, Fishel S, McDermott H, Dowell K, Hall J, Green S: A positive correlation between expression of beta I-integrin cell adhesion molecules and fertilizing ability of human spermatozoa in vitro. Hum Reprod 1995, I0(3):728-733.

18. Henkel R, Schaller J, Glander HJ, Schill WB: Low expression of adhesion molecules and matrix proteins in patients showing poor penetration in zona-free hamster oocytes. Mol Hum Reprod 1996, 2(5):335-339.

19. Reddy KV, Meherii PK, Shahani SK: Integrin cell adhesion molecules on human spermatozoa. Indian J Exp Biol 1998, 36(5):456-463.

20. Xie Y, Yue L, He Y, Zhang J, Mao R, Lei S, Zheng Y: [Study on the effect of integrin on human sperm activation]. Sichuan $D a X u e$ Xue Bao Yi Xue Ban 2003, 34(3):459-46I.

21. Evans JP, Schultz RM, Kopf GS: Mouse sperm-egg plasma membrane interactions: analysis of roles of egg integrins and the mouse sperm homologue of PH-30 (fertilin) beta. I Cell Sci 1995, 108 ( Pt 10):3267-3278.

22. Wassarman PM: Mammalian fertilization: molecular aspects of gamete adhesion, exocytosis, and fusion. Cell 1999. 96: $175-183$

23. Evans JP: Sperm disintegrins, egg integrins, and other cell adhesion molecules of mammalian gamete plasma membrane interactions. Front Biosci 1999, 4:DII4-3I.

24. Stein KK, Primakoff $P$, Myles D: Sperm-egg fusion: events at the plasma membrane. J Cell Sci 2004, I I 7(Pt 26):6269-6274.

25. Barraud-Lange $V$, Naud-Barriant N, Bomsel M, Wolf JP, Ziyyat A: Transfer of oocyte membrane fragments to fertilizing spermatozoa. Faseb J 2007.

26. Whittingham DG: Culture of mouse ova. J Reprod Fertil Suppl I97I, I4:7-2I.

27. Image]: [http://rsb.info.nih.gov/ij/].

Publish with Bio Med Central and every scientist can read your work free of charge

"BioMed Central will be the most significant development for disseminating the results of biomedical research in our lifetime. "

Sir Paul Nurse, Cancer Research UK

Your research papers will be:

- available free of charge to the entire biomedical community

- peer reviewed and published immediately upon acceptance

- cited in PubMed and archived on PubMed Central

- yours - you keep the copyright 